Review Article

\title{
Seroprevalence of Hepatitis C Viral Infection in Ethiopia: A Systematic Review and Meta-Analysis
}

\author{
Teshiwal Deress (D), ${ }^{1}$ Yihenew Million (iD), 2 Teshome Belachew ${ }^{1 D},{ }^{2}$ Mohabaw Jemal (D), \\ and Mekonnen Girma iD ${ }^{1}$ \\ ${ }^{1}$ Unit of Quality Assurance and Laboratory Management, School of Biomedical and Laboratory Sciences, \\ College of Medicine and Health Sciences, University of Gondar, Gondar, Ethiopia \\ ${ }^{2}$ Department of Medical Microbiology, School of Biomedical and Laboratory Sciences, College of Medicine and Health Sciences, \\ University of Gondar, Gondar, Ethiopia
}

Correspondence should be addressed to Teshiwal Deress; teshiwalderess@gmail.com

Received 16 September 2020; Revised 13 February 2021; Accepted 26 March 2021; Published 9 April 2021

Academic Editor: Gianandrea Pasquinelli

Copyright (c) 2021 Teshiwal Deress et al. This is an open access article distributed under the Creative Commons Attribution License, which permits unrestricted use, distribution, and reproduction in any medium, provided the original work is properly cited.

\begin{abstract}
Background. Hepatitis $\mathrm{C}$ virus is a highly genetically heterogenous bloodborne pathogen that is responsible for acute and chronic hepatitis. Globally, an estimated 71 million population is chronically infected with this virus from which 399,000 people die every year. Its prevalence is high in Ethiopia and varies from region to region, even among different studies within a region. Methods. Electronic databases, including Science Direct, Medline, HINARI, African Journals Online, TRIP database, African Index Medicus, and Directory of Open Access Journals, searched from 2010 to 2020 and published articles were included. Due to evidence of considerable heterogeneity, the pooled prevalence of anti-HCV was analyzed using the random-effects model. The possible sources of heterogeneity were analyzed through subgroup analysis, sensitivity analysis, and meta-regression. Funnel plots and Egger's test statistics were used to determine the presence of publication bias. Results. The analysis of 56 articles showed that the prevalence of anti-HCV in Ethiopia ranged from $0 \%$ to $22 \%$. The pooled prevalence estimated was 2\% (95\% CI 2.0-3.0), and the meta-regression statistics indicated that the diagnostic method $(p=0.037)$, study group $(p=0.005)$, and level of bias $(p=$ 0.035 ) showed statistically significant association with the outcome variable. The sensitivity analysis claims no influence on the overall effect estimate while removing a single study from the analysis at a time. Egger's test statistics $(p \leq 0.001)$ declare the presence of publication bias that is handled using time and fill analysis. Conclusions. The pooled prevalence of anti-HCV in Ethiopia was high. Predictor variables, including the diagnostic method, study group, and level of bias, showed a statistically significant relationship with the outcome variable. Strengthening the scope of existing prevention and control programs and implementing novel approaches, including screen-and-treat, could significantly help to tackle this critical public health issue. The study provides a current estimate which is valuable for policymakers and other responsible bodies.
\end{abstract}

\section{Background}

Hepatitis $\mathrm{C}$ virus (HCV) is an enveloped positive-sense single-stranded RNA molecule of approximately $9500 \mathrm{nu}-$ cleotides, which is grouped under the genus Hepacivirus [1]. It is genetically highly heterogenous, which is classified into seven genotypes (1-7) with approximately a hundred subtypes [2]. The virus is a bloodborne pathogen that is commonly transmitted through direct blood contact, mother to child, organ transplantations, inadequate sterilization of medical equipment, unsafe sexual practices, and intravenous drug use [3-5].

Hepatitis $\mathrm{C}$ virus is responsible for acute and chronic hepatitis [6]. It is a significant public health issue because of its chronic hepatitis that often progresses to cirrhosis and hepatocellular carcinoma [1]. The acute infection is usually an asymptomatic stage. Among HCV-infected patients, the viral particle gradually decreases in $15-25 \%$ of patients and finally disappears from the blood circulation. Though the rate of progression to chronic infection is affected by several 
factors, usually, on average, $75-85 \%$ of patients will progress to chronic disease [7]. The persistent HCV infection is typically related to the development of liver cirrhosis and hepatocellular carcinoma [8]. The severity of the infection is mainly due to its long-term hepatic and extrahepatic consequences [9]. Within twenty years of disease progression, $27 \%$ and $25 \%$ of the patients will develop liver cirrhosis and hepatocellular carcinoma, respectively [7]. The most frequent complaint in chronic HCV infection is fatigue, and other less common clinical manifestations are anorexia, weakness, nausea, arthralgia, myalgia, and weight loss [10]. The primary prevention mechanisms are essential in reducing the risks of exposure through education on safe sex, safe protocols of contaminated needle use, and blood and other body fluids [11]. Regarding diagnostic techniques, the initial screening test is the antibody test. Currently, different testing methods are available on the market, including enzyme-linked immunosorbent assay (ELISA), reverse transcription polymerase chain reaction (RT-PCR), and rapid diagnostic test (RDT) kits [12].

Hepatitis $C$ virus causes substantial morbidity and mortality worldwide $[2,13]$. An estimated 71 million population is chronically infected with the virus, and about 399,000 people die each year due to cirrhosis and liver cancer globally $[14,15]$. According to the World Health Organization (WHO) estimation, during 2015, there was 1.75 million population with new $\mathrm{HCV}$ cases globally [5]. The virus is about four times more infectious than the human immunodeficiency virus (HIV) [16]. The lack of an effective vaccination can significantly increase its burden [5]. Besides, the vast genetic diversity brings challenges to the host immune control, development of pangenotypic treatments, and patient management [17]. Hepatitis C virus infection is also a significant public health issue in Ethiopia, with its prevalence estimate ranging from $<0.5 \%[18-24]$ to $22 \%$ [25]. Even the prevalence varies from study to study within a region depending on the nature of the study participants, study setting, year of study, and other potential predictor variables. The first meta-analysis and systematic review were conducted in 2016 [26]; however, due to increased demand for current prevalence data by the health regulatory bodies to design the appropriate intervention strategies, conducting the current pooled prevalence estimate of the anti-HCV was found to be useful. Therefore, this systematic review and meta-analysis aimed to generate the pooled prevalence estimate of the anti-HCV by including a substantial number of articles published from 2010 to December 20, 2020, among the Ethiopian population.

\section{Methods}

2.1. Study Design and Protocol Registration. The protocol of the current systematic review and meta-analysis was designed following the "Preferred Reporting Items for Systematic Reviews and Meta-Analysis Protocols" (PRISMA-P 2015) guidelines [27] and prospectively registered in the PROSPERO database with the protocol registration number of CRD42020153487.
2.2. Article Searching Strategy. Before starting the actual work of the project, the Database of Abstracts of Reviews of Effects (DARE) (http://www.library.UCSF.edu) and PROSPERO databases regressively searched to check the presence of similar projects related to the topic. The literature searching strategy, selection of potentially eligible studies, data extraction, data analysis, and result reporting were performed according to the Preferred Reporting Items for Systematic Reviews and Meta-Analyses (PRISMA) guidelines [28]. Electronic databases, namely, Science Direct, Medline through PubMed, HINARI, African Journals Online (AJOL), TRIP database, African Index Medicus, and Directory of Open Access Journals (DOAJ), have been mined using a combination of keywords and Boolean operators. Keywords including hepatitis $\mathrm{C}$ virus, hepatitis $\mathrm{C}$, $\mathrm{HCV}$, viral liver disease, viral hepatitis, hepacivirus, hepatitis $\mathrm{C}$ antibodies, transfusion-transmissible infectious, prevalence, seroprevalence, epidemiology, seroepidemiology, proportion, rate, frequency, magnitude, Ethiopia, and the year of publication were used to search the mentioned databases. According to the requirements of the database, the search strings were designed with the help of librarian experts. Our Medline searching strategy is provided in Supplementary Material. Besides, to include as many articles as possible, manual hand searching on Google, Google Scholar, and screening of reference lists of both included and excluded studies were performed. All studies published from 2010 to 2020 were considered, and the most recent database search was performed on December 20, 2020.

2.3. Article Selection and Eligibility. The searched articles were imported into the EndNote X9 software, and duplicate studies were removed. All authors screened the remaining records independently by title, abstract, and full-text to identify potentially eligible studies for the review. Studies were eligible if they were primary study full-text articles conducted in Ethiopia and published in peer-reviewed journals from 2010 to 2020 in the English language. Besides, studies conducted with anti-HCV laboratory screening, prevalence data clearly stated, or if missed the presence of sufficient data to calculate the prevalence (known sample size and anti-HCV positive finding) were considered. Regarding the exclusion criteria, studies with zero and unclear prevalence and those having methodological errors were excluded from the study.

2.4. Data Extraction. The data abstraction form was prepared in a Microsoft Excel Spreadsheet which includes first author's name, year of study, publication year, region, setting (urban or rural), the HCV diagnostic method (ELISA or RDT), the study group, study design, sample size, sampling technique, and the number of anti-HCV positive cases. Two (TD and YM) authors extracted the data independently. A third author (TB) confirmed the data extraction process by taking five studies randomly and any inconsistency resolved by mutual consensus. 
2.5. Quality Assessment. The quality assessment was performed independently by two authors using the Joanna Briggs Institute (JBI) quality assessment tool for prevalence studies [29]. The instrument is composed of 9 quality domains where each item scored either positive or negative, and the importance of the items was not weighted. Higher scores (positive items) correspond to higher-quality studies for our review. We considered that the studies with scores $0-3,4-6$, and $7-9$ represented a high, moderate, and low risk of bias, respectively. The quality assessment score did not use for study selection for the present review. This variable (score in the quality evaluation of the study) was analyzed in meta-regression. The quality of data abstraction (interrater agreement) examined using Cohen's Kappa and the reliability coefficient (Kappa value) was found to be 0.827 $(p \leq 0.001)$, which indicates an excellent agreement.

2.6. Data Synthesis and Analysis. Data were analyzed using Metaprop package of Stata software which is a statistical program used to perform meta-analyses of proportions in Stata. During the analysis, the Freeman Tukey double arcsine transformation $(\mathrm{ftt})$ was enabled to include proportions close to 0 and 1 [30]. This program computes the weighted pooled estimate and then performs back-transformation on the pooled estimate. The time-transformed prevalence weighted very slightly towards $50 \%$, which enable 0 prevalence studies included in the analysis [31]. When there is evidence of a cross-study heterogeneity, the random-effects model is recommended for analysis [32]. In this case, the DerSimonian and Laird method is most commonly used [33]. The presence of heterogeneity among studies is checked using $I^{2}$ test statistics, which estimates the presence of observed differences between studies due to heterogeneity. The $I^{2}$ value can range from 0 to $100 \%$, and $0 \%$ indicates the absence of heterogeneity, whereas $100 \%$ is a definitive indicator of significant heterogeneity. The $25 \%, 50 \%$, and $75 \%$ values represent low, medium, and high heterogeneities between studies, respectively [34]. Besides, a $p$ value of $<0.05$ is used to declare the presence of heterogeneity [35]. In this meta-analysis, the $I^{2}$ value was high $(97.77 \%)$, which is $>75 \%$, an indication of considerable heterogeneity. Due to this reason, the analysis conducted using a random-effects model at $95 \% \mathrm{CI}$ as opposed to the fixed effects model to adjust the observed variability among studies. The possible sources of heterogeneity are investigated through subgroup analysis, sensitivity analysis, and meta-regression. The visual inspection of funnel plots and Egger's weighted statistics were used to investigate the presence of publication bias and small study effects. All the data management and statistical analysis performed using Stata software version 16.0 (StataCorp LLC College Station TX 77845, USA for windows version).

\section{Results}

3.1. Study Selection. Initially, 4557 studies were retrieved from the databases and hand searching. From this, 454 studies were removed due to duplication. Then, 4103 articles were screened by title/abstract, and 3953 articles were excluded because of no relevance to the current review. The remaining 150 full-text articles were further refined, and 94 of them were excluded due to being review articles, zero prevalence, articles published in nonreputable (nonpeerreviewed) journals, and studies conducted before 2010. Finally, 56 studies [18-25, 36-83] fulfilled the inclusion criteria and were included in the review (Figure 1).

\subsection{Overview of Anti-HCV Prevalence Studies. Hepatitis C} virus prevalence data and other indicators were extracted from 56 studies. The overall study participants used for the HCV screening were 710820, which was obtained from six regional states and two self-administrative cities (SAC) of the country. Studies with the smallest and largest sample sizes were 120 from the Addis Ababa city [25] and 554954 from all regions of the country [77]. All included studies were conducted with cross-sectional study designs, and the most recent studies were conducted in 2020 [77, 79, 83]. Concerning HCV study coverage in the country, the highest number of studies, 25 (44.64\%), was obtained from the Amhara region, followed by $9(16.07 \%)$ from the Southern Nations Nationalities and Peoples Regions (SNNPR). A minimal number of studies were obtained from Tigray, Gambella, Somali, and Harari regions; however, no study was obtained from Benishangul-Gumuz and Afar regions (Table 1).

There was high variability in the prevalence of anti-HCV among primary studies in Ethiopia, which can range from $0 \%[18-24,84]$ to $22 \%$ [25]. Due to the presence of considerable heterogeneity $\left(I^{2}=97.79\right)$ among the included studies, the random-effects model was used to estimate the pooled prevalence. According to the random-effects model, the pooled prevalence estimate of anti-HCV was $2 \%(95 \%$ CI: 2-3) with a $p$ value of $\leq 0.01$ (Figure 2).

\subsection{Investigation of Heterogeneity}

3.3.1. Subgroup Analysis. A subgroup analysis was performed on the study group, risk of bias, region/providence, year of publication, sampling technique, and diagnostic method. The subgroup analysis showed that the heterogeneity level slightly reduced among studies conducted on HIV-positive study participants; while in all cases, the level of heterogeneity was still high. Concerning prevalence estimates, the highest anti-HCV prevalence reported among HIV patients (4\%), studies with a high risk of bias (5\%), nonprobability sampling techniques (7\%), studies conducted in SAC (5\%), and RDT diagnostic methods (3\%) than estimates of the corresponding subgroups (Table 2).

3.3.2. Meta-Regression and Sensitivity Analysis. A metaregression analysis was performed on categorical variables, including publication year, the study group, region, sample size, sampling technique, risk of bias, and diagnostic methods. Among these predictor variables, the region was marginal $(p=0.089)$; whereas, the diagnostic method 


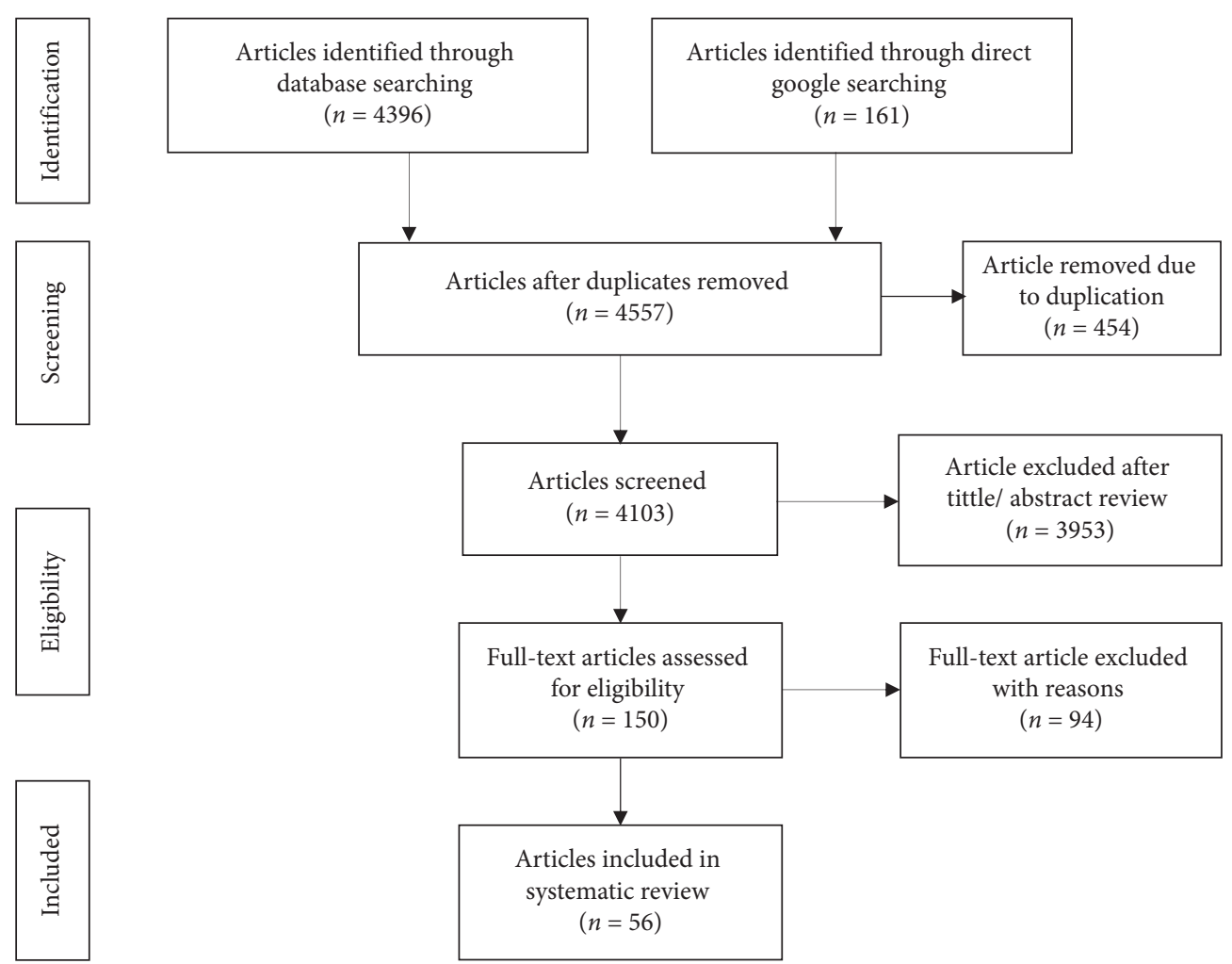

FIgURE 1: PRISMA flow diagram for identification and selection of articles for inclusion in the review.

$(p=0.037)$, study group $(p=0.005)$, and level of bias $(p=$ $0.035)$ showed a statistically significant association with the outcome variable. Furthermore, a sensitivity analysis was conducted to examine the influence of a single study on the overall effect estimate while removing a study at a time from the analysis; however, the pooled estimate did not significantly change (Table 3 ).

3.3.3. Publication Bias and Small Study Effects. Publication bias was assessed through visual inspection of the funnel plot and objectively using Egger's weighted regression statistics. Each dot in the funnel plot represented a single study, and the symmetrical distribution suggests the absence of publication bias [85]. Studies' effect sizes were plotted against the corresponding standard errors, and the visual inspection of the funnel plot showed the presence of publication bias (Figure 3).

Then, Egger's test result declared the presence of publication bias $(p \leq 0.001)$. Finally, the funnel plot was adjusted using the trim and fill analysis (Figure 4).

\section{Discussion}

Hepatitis $\mathrm{C}$ virus is a global threat that mainly affects developing countries where there is an inadequate infrastructure for prevention and control [86]. So far, studies indicated that the highest prevalence rates of $\mathrm{HCV}$ were reported from sub-Saharan Africa and Asia [87]. As a part of developing countries, HCV prevalence is high in Ethiopia and variable from region to region; even, it differs among studies conducted within an area. For this reason, generating pooled prevalence and providing detailed analysis and explanation could significantly help policymakers and other stakeholders in designing the proper strategy for intervention. The analysis of 56 full-text articles showed that the prevalence of anti-HCV ranged from $0 \%$ to $22 \%$. From this, the pooled prevalence estimate was $2 \%$, which is nearly similar to $1.9 \%, 2.5 \%$, and $2.9 \%$ of findings obtained from Yemen, Sudan, and Congo [88-90]. The current result was lower than the earlier estimate $(3.1 \%)$ conducted in the country [26], which indicates a slight decline in prevalence in the country. Probably, the decrease in the prevalence could be due to the attention given by the Federal Ministry of Health, health workers, and other responsible bodies for infection prevention and control. The result was, however, much lower than $3.4 \%, 4.8 \%, 6.2 \%, 6.5 \%$, and $11.9 \%$ findings obtained from Africa, Somalia, Pakistan, Cameroon, and Egypt [91-94]. On the other hand, the current pooled estimate is far higher than $(0.9 \%$ and $1 \%), 0.3 \%, 0.91 \%$, and $1 \%$ findings obtained from the eastern parts of Africa, Iran, China, and the global pooled estimate [15, 87, 88, 95]. The prevalence difference among the mentioned countries could be due to differences in health programs, diagnostic methods, and sociocultural practice contributed to disease transmission. Mainly, in Ethiopia, community practices such as tattooing and medical injections administered by other than health professionals are widely practiced by the Ethiopian community.

Out of fifty-six studies, six reported the prevalence of anti-HCV among HIV-positive patients. It is a fact that HIV infection potentially affects the natural history of $\mathrm{HCV}$ 
TABLE 1: Characteristics of the included studies in the systematic review and meta-analysis for the prevalence of anti-HCV in Ethiopia, 2020.

\begin{tabular}{|c|c|c|c|c|c|c|c|}
\hline $\begin{array}{l}\text { First author, publication year } \\
\text { [reference] }\end{array}$ & Region & Study group & $\begin{array}{l}\text { Sampling } \\
\text { technique }\end{array}$ & Sample & Positive & $\begin{array}{c}\text { Diagnostic } \\
\text { method }\end{array}$ & Risk of bias \\
\hline Abate and Wolde, 2016 [36] & Somali & Blood donors & Consecutive & 6827 & 99 & ELISA & Moderate \\
\hline Abebe et al., 2020 [78] & Oromia & Blood donors & Consecutive & 17810 & 114 & ELISA & \\
\hline Abera et al., 2017 [37] & Amhara & Adult population & Random & 481 & 5 & RDT & High \\
\hline Abera et al., 2014 [38] & Amhara & HIV & Random & 253 & 14 & ELISA & Moderate \\
\hline Abdella et al., 2020 [77] & $\begin{array}{l}\text { Nation- } \\
\text { wide }\end{array}$ & Blood donors & Random & 554954 & 2220 & ELISA & \\
\hline Alemayehu et al., 2011 [39] & SNNPR & Mixed & Consecutive & 800 & 66 & ELISA & Moderate \\
\hline Ameha et al., 2019 [76] & Amhara & VCT & Random & 382 & 8 & $\mathrm{RDT}$ & Moderate \\
\hline Amsalu et al., 2016 [40] & SNNPR & Mixed & Entire & 234 & 2 & RDT & High \\
\hline Anagaw et al., 2012 [18] & Amhara & Mixed & Not stated & 200 & 1 & $\mathrm{RDT}$ & High \\
\hline Asemahagn, 2020 [79] & Amhara & Surgical & Random & 422 & 18 & RDT & \\
\hline Assefa et al., 2013 [41] & Amhara & Blood donors & Entire & 2384 & 15 & ELISA & Moderate \\
\hline Ataro et al., 2018 [42] & SAC & Blood donors & Entire & 6376 & 61 & ELISA & Low \\
\hline Atsbaha et al., 2016 [43] & Tigray & Mixed & Random & 302 & 13 & $\mathrm{RDT}$ & Low \\
\hline Ayano et al., $2020[80]$ & SAC & Psychiatric & Random & 309 & 4 & ELISA & \\
\hline $\begin{array}{l}\text { Ayele and Gebre-Selassie, } 2013 \\
\text { [25] }\end{array}$ & SAC & Liver disease & Convenient & 120 & 27 & RDT & High \\
\hline Ayele et al., 2020 [81] & Gambella & Refugees & Convenient & 453 & 9 & ELISA & \\
\hline Azerefegn et al., 2018 [73] & SNNPR & Blood donors & Entire & 6849 & 48 & ELISA & Low \\
\hline Bafa and Egata, 2019 [82] & SNNPR & Pregnant women & Random & 222 & 4 & ELISA & \\
\hline Balew et al., 2014 [44] & Amhara & HIV & Random & 395 & 5 & RDT & Low \\
\hline Berhanu S, 2018 [74] & Amhara & Blood donors & Entire & 7255 & 49 & ELISA & Moderate \\
\hline Biadgo et al., 2017 [45] & Amhara & Blood donors & Entire & 6471 & 51 & ELISA & Low \\
\hline Birhaneselassie et al., 2016 [46] & SNNPR & Blood donors & Entire & 6337 & 38 & ELISA & Moderate \\
\hline Birku T, 2015 [19] & Amhara & $\begin{array}{l}\text { Military } \\
\text { personnel }\end{array}$ & Random & 403 & 1 & $\mathrm{RDT}$ & Low \\
\hline Bisetegen et al., 2016 [47] & SNNPR & Blood donors & Consecutive & 390 & 33 & ELISA & Moderate \\
\hline Dabsu Ejeta, 2018 [48] & Oromia & Pregnant women & Convenient & 421 & 34 & RDT & Low \\
\hline Dagnew M, 2020 [83] & Amhara & Pregnant women & Random & 1121 & 18 & ELISA & \\
\hline Demsiss et al., 2018 [49] & Amhara & Health students & Random & 408 & 3 & ELISA & Low \\
\hline Deressa et al., 2018 [20] & Amhara & Blood donors & Entire & 8460 & 27 & ELISA & Low \\
\hline Ejeta and Dabsu, 2019 [50] & Oromia & Pregnant women & Consecutive & 421 & 34 & ELISA & Low \\
\hline Gebrekristos et al., 2018 [51] & Tigray & Mixed & Not stated & 460 & 77 & ELISA & High \\
\hline Hadush et al., 2013 [52] & Tigray & Mixed & Not stated & 300 & 18 & ELISA & High \\
\hline Hebo et al., 2019 [21] & Oromia & Health workers & Random & 240 & 1 & ELISA & Low \\
\hline Heyredin et al., 2019 [53] & Mixed & Blood donors & Consecutive & 500 & 5 & ELISA & Low \\
\hline Juhar et al., 2018 [54] & SAC & Hemodialysis & Not stated & 253 & 7 & ELISA & High \\
\hline Kebede et al., 2017 [55] & Oromia & Prisoner & Random & 156 & 4 & ELISA & Moderate \\
\hline Manyazewal et al., 2014 [56] & SAC & Mixed & Not stated & 500 & 18 & ELISA & Low \\
\hline Mekonnen et al., 2015 [57] & SAC & Waste handlers & Random & 252 & 4 & ELISA & Low \\
\hline Metaferia et al., 2018 [58] & Amhara & Pregnant women & Consecutive & 385 & 5 & RDT & Low \\
\hline Million et al., 2019 [75] & Amhara & Mixed & Convenient & 610 & 30 & ELISA & Low \\
\hline Mohammed and Bekele, 2016 [22] & Somali & Blood donors & Entire & 4224 & 17 & ELISA & Moderate \\
\hline Molla et al., 2015 [23] & Amhara & Pregnant women & Random & 384 & 1 & $\mathrm{RDT}$ & Low \\
\hline Mulu et al., 2013 [59] & Amhara & HIV & Not stated & 269 & 8 & ELISA & High \\
\hline Negash et al., 2019 [60] & Amhara & Blood donors & Consecutive & 310 & 13 & ELISA & Low \\
\hline Seid et al., 2014 [61] & Amhara & Pregnant women & Random & 385 & 8 & RDT & Low \\
\hline Shiferaw et al., 2019 [62] & Amhara & Blood donors & Entire & 35435 & 213 & ELISA & Low \\
\hline Shimelis et al., 2019 [63] & SNNPR & HIV & Not stated & 477 & 15 & RDT & Low \\
\hline Taye et al., 2019 [64] & SNNPR & Surgery patients & Random & 422 & 23 & RDT & Moderate \\
\hline Taye et al., 2014 [65] & SNNPR & Chronic hepatitis & Not stated & 220 & 8 & $\mathrm{RDT}$ & High \\
\hline Taye and Lakew, 2013 [66] & SAC & HIV & Nonprobability & 387 & 25 & $\mathrm{RDT}$ & Moderate \\
\hline Teklemariam et al., 2018 [67] & Harari & Blood donors & Entire & 11382 & 91 & ELISA & Low \\
\hline Tesfa et al., 2013 [68] & Amhara & General & Entire & 2684 & 332 & RDT & Moderate \\
\hline Tessema et al., 2010 [69] & Amhara & Blood donors & Consecutive & 6361 & 45 & ELISA & Low \\
\hline Tigabu et al., 2019 [70] & Amhara & Blood donors & Entire & 5983 & 96 & ELISA & Low \\
\hline Wondimeneh et al., 2013 [71] & Amhara & HIV & Not stated & 400 & 18 & $\mathrm{RDT}$ & Low \\
\hline Yami et al., 2011 [24] & Oromia & Blood donors & Random & 6063 & 10 & ELISA & Low \\
\hline Zenebe et al., 2015 [72] & Amhara & Pregnant women & Nonprobability & 318 & 2 & ELISA & Moderate \\
\hline
\end{tabular}

SAC, self-administrative cities (Addis Ababa and/or Dire Dawa); ELISA, enzyme-linked immunosorbent assay; RDT, rapid diagnostic test; SNNPR, Southern Nations, Nationalities and Peoples Region; HIV, human immune virus; VCT, voluntary counseling and testing. 


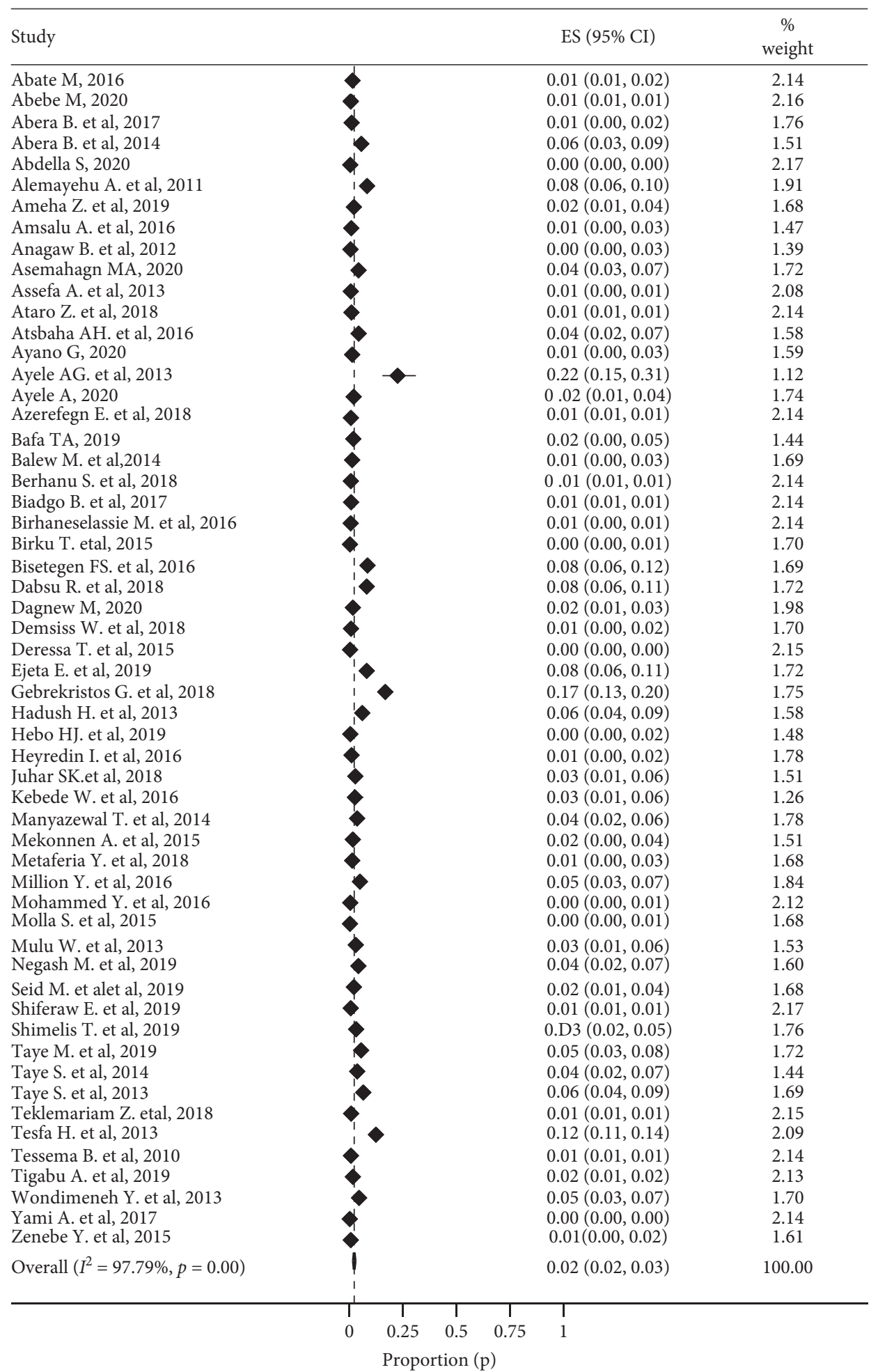

FIgure 2: Poole prevalence of anti-HCV in Ethiopia from 2010 to 2020.

infection. Findings indicated that nearly one-third of HIVuninfected persons spontaneously clear HCV infection in the first year; however, HCV coinfection with HIV significantly reduces the clearance rate of $\mathrm{HCV}$ viral particles from the blood circulation. In the current review, the prevalence estimate of anti-HCV among HIV-positive patients was $4 \%$, which is similar to the global pooled estimate of $2.4 \%$ [96]. This high prevalence could be attributed due to the high burden of coinfection in the area, although the result showed a considerable decline compared to the previous estimate (5.5\%) [26]. The decrease in the prevalence could be due to factors including mortality of the infected population, 
TABLE 2: Subgroup analysis of the anti-HCV pooled prevalence estimation in Ethiopia, 2020.

\begin{tabular}{|c|c|c|c|c|c|}
\hline Predictor variables & Variable category & Included studies & ES $(95 \%$ CI $)$ & $I^{2} \%$ & $p$ value \\
\hline \multirow{5}{*}{ Study group } & Blood donor & 19 & $0.01(0.01,0.01)$ & 95.96 & $\leq 0.001$ \\
\hline & HIV positive & 6 & $0.04(0.02,0.06)$ & 74.13 & $\leq 0.001$ \\
\hline & Pregnant women & 8 & $0.02(0.01,0.05)$ & 91.83 & $\leq 0.001$ \\
\hline & Mixed groups & 8 & $0.05(0.02,0.08)$ & 93.76 & $\leq 0.001$ \\
\hline & Others & 15 & $0.03(0.01,0.06)$ & 96.48 & $\leq 0.001$ \\
\hline \multirow{3}{*}{ Risk of bias } & Low & 32 & $0.02(0.01,0.02)$ & 95.88 & $\leq 0.001$ \\
\hline & Moderate & 16 & $0.03(0.01,0.04)$ & 98.56 & $\leq 0.001$ \\
\hline & High & 9 & $0.05(0.02,0.09)$ & 95.30 & $\leq 0.001$ \\
\hline \multirow{5}{*}{ Region/city } & Amhara & 25 & $0.02(0.01,0.02)$ & 97.67 & $\leq 0.001$ \\
\hline & Oromia & 6 & $0.02(0.01,0.04)$ & 97.36 & $\leq 0.001$ \\
\hline & SNNPR & 9 & $0.03(0.01,0.05)$ & 96.79 & $\leq 0.001$ \\
\hline & Self-administrative city & 7 & $0.05(0.02,0.09)$ & 95.97 & $\leq 0.001$ \\
\hline & Others & 9 & $0.02(0.01,0.03)$ & 97.96 & $\leq 0.001$ \\
\hline \multirow{3}{*}{ Year of publication } & $2010-2012$ & 3 & $0.02(0.00,0.09)$ & - & - \\
\hline & 2013-2015 & 16 & $0.03(0.01,0.06)$ & 98.39 & $\leq 0.001$ \\
\hline & $2016-2020$ & 37 & $0.02(0.01,0.02)$ & 96.75 & $\leq 0.001$ \\
\hline \multirow{4}{*}{ Sampling techniques } & Probability & 19 & $0.02(0.01,0.02)$ & 92.22 & $\leq 0.001$ \\
\hline & Entire sampling & 23 & $0.02(0.01,0.02)$ & 98.19 & $\leq 0.001$ \\
\hline & Nonprobability & 7 & $0.02(0.02,0.09)$ & 97.55 & $\leq 0.001$ \\
\hline & Not stated & 7 & $0.05(0.02,0.09)$ & 93.65 & $\leq 0.001$ \\
\hline \multirow{2}{*}{ Diagnostic method } & ELISA & 37 & $0.02(0.01,0.02)$ & 96.88 & $\leq 0.001$ \\
\hline & RDT & 19 & $0.03(0.02,0.06)$ & 95.90 & $\leq 0.001$ \\
\hline
\end{tabular}

ELISA, enzyme-linked immunosorbent assay; RDT, rapid diagnostic test; SNNPR, Southern Nations, Nationalities and Peoples Region.

TABLE 3: Meta-regression analysis of factors for the heterogeneity of anti-HCV prevalence in Ethiopia, 2020.

\begin{tabular}{lcccc}
\hline Predictor & Coefficient & Std. error & $\begin{array}{c}p \\
\text { value }\end{array}$ & $\begin{array}{c}\text { Adjusted } R^{2} \\
(\%)\end{array}$ \\
\hline Sample size & $-3.30 e-06$ & $2.04 e-06$ & 0.112 & -0.58 \\
Publication year & -0.0693 & 0.0605 & 0.257 & 1.34 \\
Region & 0.1790 & 0.1034 & 0.089 & 0.39 \\
Study group & 0.2916 & 0.0989 & $0.005^{*}$ & 17.66 \\
$\begin{array}{l}\text { Diagnostic } \\
\text { method }\end{array}$ & 0.7042 & 0.3284 & $0.037^{*}$ & -9.26 \\
Level bias & 0.4482 & 0.2066 & $0.035^{*}$ & 9.04 \\
\hline
\end{tabular}

*Statistically significant association.

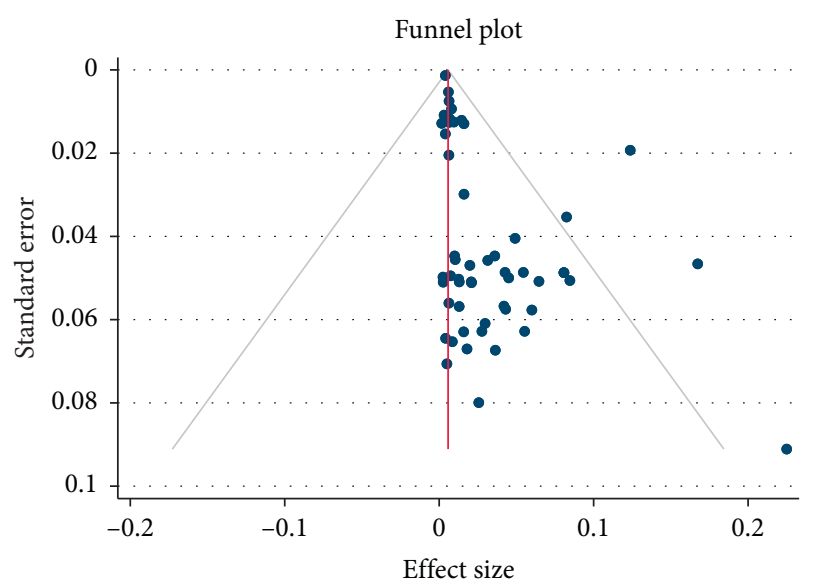

FIGURE 3: Funnel plot of anti-HCV prevalence in Ethiopia published from 2010 to 2020 .

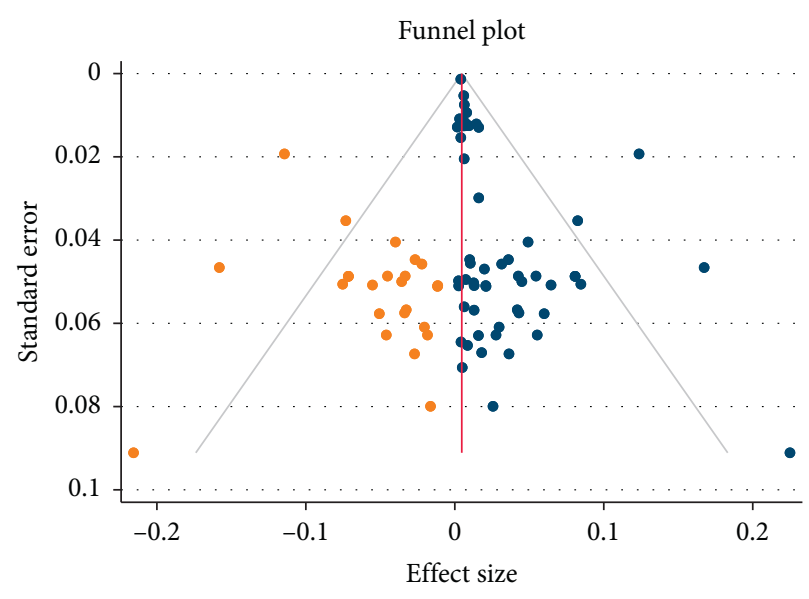

Figure 4: Trim and fill analysis of anti-HCV prevalence studies in Ethiopia published from 2010 to 2020 .

reduction of new cases because of the implementation of blood supply screening, and decline of high-risk behaviors among the community. On the other hand, quite higher findings were obtained from Cameroon (7.13\%), subSaharan regions (7\%), and Iran (10.95\%) [94, 97, 98]. The 2\% pooled estimate among the pregnant women is quite similar to findings from Congo (3.3\%) and Cameroon (3\%), but higher than a study from Sudan $(0.6 \%)[89,90,94]$. The result was, however, much lower than the pooled global estimate (6.4\%) and a finding from Egypt (9\%) [96, 99].

In Ethiopia, infectious diseases that can be transmitted through blood transfusion have been prevented by excluding blood donors having specific risk factors, using healthy donors, screening donated blood with reliable screening 
techniques, and maintaining good hygienic practices. Despite several interventions implemented so far, HCV is still a significant public health issue in the country. The insignificant decline of the prevalence could be due to the nature of the infection (chronic infection) that has the potential to transmit the disease to the healthy person and the lack of an effective vaccine to prevent the incidence of new cases. Considering the vast population of the country, a prevalence of $1 \%$ (our result) leads to thousands and even hundreds of thousands of seropositive patients. In the current study, the prevalence of viral markers among blood donors is much lower than the general population; this could be due to donors selected from populations with the low risk of infectious diseases due to donor health assessment. This result is far lower than findings from Congo (2.7\%), Cameroon (2.49\%), Egypt (10.4\%), and China $(8.68 \%)[90,94,99,100]$; however, it is higher than $0.5 \%$ a finding from Iran [101]. According to study quality, the highest prevalence of anti-HCV (5\%) was noted among studies that have a high risk of bias in their method compared to low risk of bias studies (2\%). The current estimate showed a significant difference to the diagnostic method in anti-HCV prevalence, and studies conducted using rapid diagnostic test kits showed a higher estimate $(3 \%)$ than studies conducted using ELISA (2\%). This difference could be since rapid diagnostic tests might lack specificity compared to ELISA tests and wrongly increased the prevalence. Hence, studies conducted with molecular techniques alone stand for the actual prevalence estimate.

According to the meta-regression analysis, the prevalence of anti-HCV in Ethiopia has significantly reduced as the studies used ELISA instead of a rapid test for the diagnosis of anti-HCV.

Regarding the risk of bias, when the bias level of the included studies increases, the prevalence estimate substantially increases. Besides, study groups of the articles included had a statistically significant relationship with the pooled prevalence estimate.

This review article incurred several limitations that should be acknowledged. The first limitation is the lack of including unpublished studies. Among the included studies, nine of them had a high level of bias. Besides, a substantial number of studies were undertaken on blood donors, which potentially underestimate the national anti-HCV pooled prevalence. The other drawback is the presence of considerable statistical heterogeneity among the included studies. Besides, there were limited studies obtained from several regions that could compromise the representativeness of the pooled estimate.

\section{Conclusions}

Even though several approaches increase diagnosis, treatment, and prevention through health education for the last decade, the result of this review showed that HCV is still a significant public health issue in Ethiopia. Studies that used rapid tests instead of ELISA (golden method) for the diagnosis of anti-HCV positively affected the pooled estimate. Besides, the study group and level of bias showed a relationship with the pooled prevalence estimate. Strengthening the scope of existing prevention and control programs is recommended. Besides, implementing novel approaches, including screen-and-treat, could significantly help to reduce the burden of HCV disease in Ethiopia. Further political will and strong community awareness could be critical to effectively tackling the burden of HCV. This study has a serious limitation, since many included studies have extremely low prevalences and extremely narrow confidence intervals; we are aware that in similar circumstances, the power of the meta-analysis is low and interpretation of the results may be misleading.

\section{Abbreviations}

AJOL: African Journals Online

DARE: Database of Abstracts of Reviews of Effects

ELISA: Enzyme-linked immunosorbent assay

HCV: Hepatitis $C$ virus

HIV: Human immunodeficiency virus

JBI: Joanna Briggs Institute

PRISMA: Preferred Reporting Items for Systematic Reviews and Meta-Analyses

RDT: $\quad$ Rapid diagnostic tests

RT-PCR: Reverse transcription polymerase chain reaction

SNNPR: Southern Nations, Nationalities and Peoples Region

VCT: Volunteer for counseling and testing

WHO: World Health Organization.

\section{Data Availability}

The data generated or analyzed during this study are included within the article.

\section{Conflicts of Interest}

The authors declare that they have no conflicts of interest.

\section{Authors' Contributions}

TD and MG conceptualized the draft protocol of the review. All authors searched databases and screened articles based on the eligibility criteria. Three (TD, YM, and TB) authors were involved in the data extraction process. TD, MG, and MJ contributed to the statistical analysis and interpretation of the results. All authors equally involved in the write-up of the draft of the article. TD finalized the article, and TD, YM, and MJ participated in the correction of the reviewer's comments. All authors read and approved the final draft of the article before submission.

\section{Acknowledgments}

The authors would like to acknowledge all authors of the primary studies and biomedical staff for reviewing the article.

\section{Supplementary Materials}

Medline search strategy. (Supplementary Materials) 


\section{References}

[1] V. A. Morozov and S. Lagaye, "Hepatitis C virus: morphogenesis, infection and therapy," World Journal of Hepatology, vol. 10, no. 2, pp. 186-212, 2018.

[2] G. B. Hundie, V. S. Raj, D. GebreMichael, S. D. Pas, and B. L. Haagmans, "Genetic diversity of hepatitis $\mathrm{C}$ virus in Ethiopia,” PLoS One, vol. 12, Article ID e0179064, 2017.

[3] C. Reker and K. M. Islam, "Risk factors associated with high prevalence rates of hepatitis C infection in Egypt," International Journal of Infectious Diseases, vol. 25, p. 106, 2014.

[4] S. M. Alavian, B. Hajarizadeh, M. Ahmadzad-asl, A. Kabir, and L. K. Bagheri-, "Hepatitis B Virus infection in Iran: a systematic review," Hepatitis Monthly, vol. 8, pp. 281-294, 2008.

[5] WHO hepatitis C key facts, https://www.who.int/newsroom/fact-sheets/detail/hepatitis-c, 2019.

[6] J. D. Stanaway, A. D. Flaxman, M. Naghavi et al., "The global burden of viral hepatitis from 1990 to 2013: findings from the Global Burden of Disease Study 2013," The Lancet, vol. 388, no. 10049, pp. 1081-1088, 2016.

[7] S. L. Chen and T. R. Morgan, "The natural history of hepatitis $\mathrm{C}$ virus (HCV) infection," International Journal of Medical Sciences, vol. 3, no. 2, p. 47, 2006.

[8] G. M. Lauer and B. D. Walker, "Hepatitis C virus infection," New England Journal of Medicine, vol. 345, no. 1, pp. 41-52, 2001.

[9] A. J. Van der Meer, B. J. Veldt, J. J. Feld et al., “Association between sustained virological response and all-cause mortality among patients with chronic hepatitis $\mathrm{C}$ and advanced hepatic fibrosis," JAMA, vol. 308, no. 24, pp. 2584-2593, 2012.

[10] B. M. R. Spiegel, Z. M. Younossi, R. D. Hays, D. Revicki, S. Robbins, and F. Kanwal, "Impact of hepatitis $\mathrm{C}$ on health related quality of life: a systematic review and quantitative assessment," Hepatology, vol. 41, no. 4, p. 790, 2005.

[11] E. Kassa, A. Bane, and H. Kefene, "Common genotypes and treatment outcomes of HCV infection among Ethiopian patients: a prospective study," Ethiopian Medical Journal, vol. 54, no. 1, pp. 1-7, 2016.

[12] Centers for Disease Control and Prevention (CDC), "Testing for HCV infection: an update of guidance for clinicians and laboratorians," Morbidity and Mortality Weekly Report, vol. 62, pp. 362-365, 2013.

[13] P. Simmonds, B. Irvine, P. L. Yap et al., "Classification of hepatitis $\mathrm{C}$ virus into six major genotypes and a series of subtypes by phylogenetic analysis of the NS-5 region," Journal of General Virology, vol. 74, no. 11, p. 2391, 1993.

[14] World Health Organization, Hepatitis C, Fact Sheet, World Health Organization, Geneva, Switzerland, 2018, http:// www.who.int/mediacentre/factsheets/fs164/en/.

[15] S. Blach, S. Zeuzem, M. Manns et al., "Global prevalence and genotype distribution of hepatitis $C$ virus infection in 2015: a modelling study," The Lancet Gastroenterology and Hepatology, vol. 2, pp. 161-176, 2017.

[16] V. Madhava, C. Burgess, and E. Drucker, "Epidemiology of chronic hepatitis C virus infection in sub-Saharan Africa," The Lancet Infectious Diseases, vol. 2, pp. 293-302, 2012.

[17] J. Timm and M. Roggendorf, "Sequence diversity of hepatitis C virus: implications for immune control and therapy," World Journal of Gastroenterology, vol. 13, no. 36, pp. 4808-4817, 2007.

[18] B. Anagaw, Y. Shiferaw, B. Anagaw et al., "Seroprevalence of hepatitis $\mathrm{B}$ and $\mathrm{C}$ viruses among medical waste handlers at
Gondar town Health institutions, Northwest Ethiopia," BMC Research Notes, vol. 5, p. 55, 2012.

[19] T. Birku, B. Gelaw, F. Moges, and A. Assefa, "Prevalence of hepatitis $\mathrm{B}$ and $\mathrm{C}$ viruses infection among military personnel at Bahir dar armed forces general hospital, Ethiopia," BMC Research Notes, vol. 8, p. 737, 2015.

[20] T. Deressa, W. Birhan, B. Enawgaw et al., "Proportion and predictors of transfusion-transmissible infections among blood donors in North Shewa Zone, Central North Ethiopia," PLoS One, vol. 13, Article ID e0194083, 2018.

[21] H. J. Hebo, D. H. Gemeda, and K. A. Abdusemed, "Hepatitis $B$ and $C$ viral infection: prevalence, knowledge, attitude, practice, and occupational exposure among healthcare workers of jimma university medical center, southwest Ethiopia," The Scientific World Journal, vol. 2019, Article ID 9482607, 11 pages, 2019.

[22] Y. Mohammed and A. Bekele, "Seroprevalence of transfusion transmitted infection among blood donors at Jijiga blood bank, Eastern Ethiopia: retrospective 4 years study," BMC Research Notes, vol. 9, p. 129, 2016.

[23] S. Molla, A. Munshea, and E. Nibret, "Seroprevalence of hepatitis B surface antigen and anti HCV antibody and its associated risk factors among pregnant women attending maternity ward of Felege Hiwot Referral Hospital, northwest Ethiopia: a cross-sectional study," Virology Journal, vol. 12, p. 204, 2015.

[24] A. Yami, F. Alemseged, and A. Hassen, "Hepatitis B and C viruses infections and their association with human immunodeficiency virus: a cross-sectional study among blood donors in Ethiopia," Ethiopian Journal of Health Sciences, vol. 21, pp. 67-75, 2011.

[25] A. G. Ayele and S. Gebre-Selassie, "Prevalence and risk factors of hepatitis B and hepatitis C virus infections among patients with chronic liver diseases in public hospitals in Addis Ababa, Ethiopia," ISRN Tropical Medicine, vol. 2013, Article ID 563821, 7 pages, 2013.

[26] Y. Belyhun, M. Maier, A. Mulu, E. Diro, and U. G. Liebert, "Hepatitis viruses in Ethiopia: a systematic review and metaanalysis," BMC Infect Dis, vol. 16, p. 761, 2016.

[27] L. Shamseer, D. Moher, M. Clarke et al., "Preferred reporting items for systematic review and meta-analysis protocols (PRISMA-P) 2015: elaboration and explanation," British Medical Journal, vol. 349, p. 7647, 2015.

[28] D. Moher, A. Liberati, J. Tetzlaff, D. G. Altman, and P. Group, "Preferred reporting items for systematic reviews and meta-analyses: the PRISMA statement," PLoS Medicine, vol. 6, Article ID e1000097, 2009.

[29] Z. Munn, S. Moola, K. Lisy, D. Riitano, and C. Tufanaru, "Methodological guidance for systematic reviews of observational epidemiological studies reporting prevalence and incidence data," International Journal of Evidence-Based Healthcare, vol. 13, no. 3, pp. 147-153, 2015.

[30] V. N. Nyaga, M. Arbyn, and M. Aerts, "Metaprop: a stata command to perform meta-analysis of binomial data," Archives of Public Health, vol. 72, p. 39, 2014.

[31] R. DerSimonian and N. Laird, "Meta-analysis in clinical trials," Controlled Clinical Trials, vol. 7, no. 3, pp. 177-188, 1986.

[32] M. Borenstein, L. V. Hedges, J. P. Higgins, and H. R. Rothstein, Introduction to Meta-Analysis, John Wiley \& Sons, Hoboken, NJ, USA, 2009.

[33] B. J. George and I. B. Aban, "An application of meta-analysis based on DerSimonian and Laird method," Journal of $\mathrm{Nu}$ clear Cardiology, vol. 23, no. 4, pp. 690-692, 2016. 
[34] A. E. Ades, G. Lu, and J. P. T. Higgins, “The interpretation of random-effects meta-analysis in decision models," Medical Decision Making, vol. 25, no. 6, pp. 646-654, 2005.

[35] J. Wang, X. Wu, W. Lai et al., "Prevalence of depression and depressive symptoms among outpatients: a systematic review and meta-analysis," BMJ Open, vol. 7, Article ID e017173, 2017.

[36] M. Abate and T. Wolde, "Seroprevalence of human immunodeficiency virus, hepatitis $B$ virus, hepatitis $C$ virus, and syphilis among blood donors at jigjiga blood bank, eastern Ethiopia," Ethiopian Journal of Health Sciences, vol. 26, no. 2, pp. 153-160, 2016.

[37] B. Abera, Y. Adem, M. Yimer, W. Mulu, Y. Zenebe, and Z. Mekonnen, "Community seroprevalence of hepatitis B, C and human immunodeficiency virus in adult population in gojjam zones, northwest Ethiopia," Virology Journal, vol. 14, p. 21, 2017.

[38] B. Abera, Y. Zenebe, W. Mulu, M. Kibret, and G. Kahsu, "Seroprevalence of hepatitis B and C viruses and risk factors in HIV infected children at the felgehiwot referral hospital, Ethiopia," BMC Research Notes, vol. 7, no. 1, p. 838, 2014.

[39] A. Alemayehu, Y. Tassachew, Z. Sisay, and T. Shimelis, "Prevalence and risk factors of Hepatitis $\mathrm{C}$ among individuals presenting to HIV testing centers, Hawassa city, Southern Ethiopia," BMC Research Notes, vol. 4, p. 193, 2011.

[40] A. Amsalu, M. Worku, E. Tadesse, and T. Shimelis, "The exposure rate to hepatitis $\mathrm{B}$ and $\mathrm{C}$ viruses among medical waste handlers in three government hospitals, southern Ethiopia," Epidemiology and Health, vol. 38, Article ID e2016001, 2016.

[41] A. Assefa, B. Mathewos, A. Alemu, Z. Addis, M. Alem, and M. Gizachew, "Hepatitis B and C viral infections among blood donors at Bahir Dar, Ethiopia," International Journal of Medical Research \& Health Sciences, vol. 2, no. 3, pp. 624-630, 2013.

[42] Z. Ataro, F. Urgessa, and T. Wasihun, "Prevalence and trends of major transfusion transmissible infections among blood donors in Dire Dawa blood bank, eastern Ethiopia: retrospective study," Ethiopian Journal of Health Sciences, vol. 28, no. 6, pp. 701-710, 2018.

[43] A. H. Atsbaha, T. A. Dejen, R. Belodu, K. Getachew, M. Saravanan, and A. G. Wasihun, "Sero-prevalence and associated risk factors for hepatitis $\mathrm{C}$ virus infection among voluntary counseling testing and anti retroviral treatment clinic attendants in Adwa hospital, northern Ethiopia," BMC Research Notes, vol. 9, p. 121, 2016.

[44] M. Balew, F. Moges, G. Yismaw, and C. Unakal, "Assessment of hepatitis $B$ virus and hepatitis $C$ virus infections and associated risk factors in HIV infected patients at Debretabor hospital, South Gondar, Northwest Ethiopia," Asian Pacific Journal of Tropical Disease, vol. 4, no. 1, pp. 1-7, 2014.

[45] B. Biadgo, E. Shiferaw, B. Woldu, K. A. Alene, and M. Melku, "Transfusion-transmissible viral infections among blood donors at the North Gondar district blood bank, northwest Ethiopia: a three year retrospective study," PLoS One, vol. 12, Article ID e0180416, 2017.

[46] M. Birhaneselassie, "Prevalence of transfusion-transmissible infections in donors to an Ethiopian blood bank between 2009 and 2013 and donation factors that would improve the safety of the blood supply in underdeveloped countries," Laboratory Medicine, vol. 47, no. 2, pp. 134-139, 2016.

[47] F. S. Bisetegen, F. B. Bekele, T. A. Ageru, and F. W. Wada, "Transfusion-transmissible infections among voluntary blood donors at wolaita sodo university teaching referral hospital, South Ethiopia," Canadian Journal of Infectious Diseases and Medical Microbiology, vol. 2016, Article ID 8254343, 6 pages, 2016.

[48] R. Dabsu and E. Ejeta, "Seroepidemiology of hepatitis B and $\mathrm{C}$ virus infections among pregnant women attending antenatal clinic in selected health facilities in east wollega zone, West Oromia, Ethiopia," BioMed Research International, vol. 2018, Article ID 4792584, 9 pages, 2018.

[49] W. Demsiss, A. Seid, and T. Fiseha, "Hepatitis B and C: seroprevalence, knowledge, practice and associated factors among medicine and health science students in Northeast Ethiopia," PLoS One, vol. 13, Article ID e0196539, 2018.

[50] E. Ejeta and R. Dabsu, "Prevalence of hepatitis C virus and HIV infection among pregnant women attending antenatal care clinic in western Ethiopia," Frontiers in Medicine, vol. 5, p. 366, 2019.

[51] G. Gebrekristos, M. Teweldemedhin, L. Hagos, T. Gebrewahid, B. Gidey, and H. Gebreyesus, "Hepatitis C virus infections and associated risk factors in patients with diabetes mellitus; case control study in North West Tigray, Ethiopia," BMC Research Notes, vol. 11, p. 873, 2018.

[52] H. Hadush, H. Gebre-Selassie, and A. Mihret, "Hepatitis C virus and human immunodeficiency virus coinfection among attendants of voluntary counseling and testing centre and HIV follow up clinics in mekelle hospital," Pan African Medical Journal, vol. 14, p. 107, 2013.

[53] I. Heyredin, B. Mengistie, and F. Weldegebreal, "Seroprevalence of transfusiontransmittable infections and associated factors among blood donors in Eastern Ethiopia: an Institutional-based cross-sectional study," SAGE Open Medicine, vol. 7, pp. 1-8, 2019.

[54] S. K. Juhar, N. Nurahmed, S. Kebede, M. Getahun, T. Arega, and A. M. Abdi, "Prevalence of hepatitis B and C viruses infections among hemodialysis patients in Addis Ababa, Ethiopia," Journal of Interventional Nephrology, vol. 1, pp. 08-14, 2018.

[55] W. Kebede, A. Abdissa, A. Abdissa, Y. Seid, and Z. Mekonnen, "Seroprevalence and risk factors of hepatitis B, hepatitis C and HIV infections among prisoners in Jimma Town, Southwest Ethiopia," Asian Pacific Journal of Tropical Disease, vol. 7, no. 5, pp. 270-275, 2017.

[56] T. Manyazewal, Z. Sisay, S. Biadgilign, and W. E. Abegaz, "Hepatitis B and hepatitis C virus infections among antiretroviral-naive and -experienced HIV co-infected adults," Journal of Medical Microbiology, vol. 63, no. 5, pp. 742-747, 2014.

[57] A. Mekonnen, K. Desta, and E. Damtew, "Prevalence of $\mathrm{HBV}, \mathrm{HCV}$ and associated risk factors among cleaners at selected public health centers in Addis Ababa, Ethiopia," International Journal of Basic and Applied Virology, vol. 4, pp. 35-40, 2015.

[58] Y. Metaferia, D. Tsegaye, E. Kebede, and A. Seid, "Seroprevalence and predictors of hepatitis B virus and hepatitis $\mathrm{C}$ virus infections among pregnant women attending antenatal care in adjibar rural health center, northeast Ethiopia," EC Gynaecology, vol. 7, pp. 421-430, 2018.

[59] W. Mulu, B. Gidey, A. Chernet, G. Alem, and B. Abera, "Hepatotoxicity and associated risk factors in HIV-infected patients receiving antiretroviral therapy at Felege Hiwot referral Hospital, Bahirdar, Ethiopia," Ethiopian Journal of Health Sciences, vol. 23, pp. 217-226, 2013.

[60] M. Negash, M. Ayalew, D. Geremew, and M. Workineh, "Seroprevalence and associated risk factors for HIV, hepatitis $\mathrm{B}$ and $\mathrm{C}$ among blood donors in south gondar district blood 
bank, northwest Ethiopia," BMC Infectious Diseases, vol. 19, p. 430, 2019.

[61] M. Seid, B. Gelaw, and A. Assefa, "Sero-prevalence of HBV and HCV infections among pregnant women attending antenatal care clinic at dessie referral hospital, Ethiopia," Advances in Life Sciences and Health, vol. 1, pp. 109-120, 2014.

[62] E. Shiferaw, W. Tadilo, I. Melkie, and M. Shiferaw, "Seroprevalence and trends of transfusion-transmissible infections among blood donors at Bahir Dar district blood bank, Northwest Ethiopia: a four year retrospective study," PLoS One, vol. 14, Article ID e0214755, 2019.

[63] T. Shimelis, Y. Tassachew, A. Tadewos et al., "Coinfections with Hepatitis B and C virus and syphilis among HIV-infected clients in Southern Ethiopia: a cross-sectional study," HIV/AIDS-Research and Palliative, vol. 9, pp. 203-210, 2017.

[64] M. Taye, D. Daka, A. Amsalu, and S. Hussen, "Magnitude of hepatitis $\mathrm{B}$ and $\mathrm{C}$ virus infections and associated factors among patients scheduled for surgery at Hawassa University comprehensive specialized Hospital, Hawassa City, Southern Ethiopia," BMC Research Notes, vol. 12, p. 412, 2019.

[65] S. Taye, A. Abdulkerim, and M. Hussen, "Prevalence of hepatitis $\mathrm{B}$ and $\mathrm{C}$ virus infections among patients with chronic hepatitis at Bereka Medical Center, Southeast Ethiopia: a retrospective study," BMC Research Notes, vol. 7, p. 272, 2014.

[66] S. Taye and M. Lakew, "Impact of hepatitis C virus co-infection on HIV patients before and after highly active antiretroviral therapy: an immunological and clinical chemistry observation, Addis Ababa, Ethiopia," BMC Immunology, vol. 14, p. 23, 2013.

[67] Z. Teklemariam, H. Mitiku, and F. Weldegebreal, "Seroprevalence and trends of transfusion transmitted infections at Harar blood bank in Harari regional state, Eastern Ethiopia: eight years retrospective study," BMC Hematology, vol. 18, p. 24, 2018.

[68] H. Tesfa, B. Biadgo, F. Getachew, K. Tegegne, G. Yismaw, and D. Muluye, "Seroprevalence of hepatitis B and C virus infection among patients attending serology laboratory of Gondar University Hospital," BMC Research Notes, vol. 6, no. 1, p. 164, 2013.

[69] B. Tessema, G. Yismaw, A. Kassu et al., "Seroprevalence of HIV, HBV, HCV and syphilis infections among blood donors at Gondar University Teaching Hospital, Northwest Ethiopia: declining trends over a period of five years," BMC Infectious Diseases, vol. 10, p. 111, 2010.

[70] A. Tigabu, T. Engda, and F. Mekonnen, "Seroprevalence of transfusion transmissible viral infections (HIV, HBV and HCV) among voluntary blood donors at University of Gondar Comprehensive Specialized Hospital, Gondar; Northwest Ethiopia," BMC Infectious Diseases, vol. 19, p. 393, 2019.

[71] Y. Wondimeneh, M. Alem, F. Asfaw, and Y. Belyhun, "HBV and HCV seroprevalence and their correlation with CD4 cells and liver enzymes among HIV positive individuals at University of Gondar Teaching Hospital, Northwest Ethiopia," Virology Journal, vol. 10, p. 171, 2013.

[72] Y. Zenebe, W. Mulu, M. Yimer, and B. Abera, "Sero-prevalence and risk factors of hepatitis $\mathrm{C}$ virus infection among pregnant women in Bahir Dar city, Northwest Ethiopia: cross sectional study," Pan African Medical Journal, vol. 21, p. 158, 2015.
[73] E. Azerefegn, M. Worku, and M. Hailemariam, "Transfusion-transmissible infections among blood donors at hawassa regional blood bank center, south Ethiopia," International Journal of Research Studies in Microbiology and Biotechnology, vol. 4, pp. 10-16, 2018.

[74] S. Berhanu, S. Abebaw, and A. Digissie, "Transfusiontransmissible infections among voluntary blood donors at debre tabor blood bank, north west Ethiopia: a three years retrospective study," Health Care Current Reviews, vol. 6, p. 236, 2018.

[75] Y. Million, T. Teklu, S. Alemu, A. Ferede, T. Belachew, and K. Desta, "Hepatitis B and hepatitis C viral infections and associated factors among patients with diabetes visiting gondar referral teaching hospital, northwest Ethiopia: a comparative cross-sectional study," Journal of Hepatocellular Carcinoma, vol. 6, pp. 143-150, 2019.

[76] Z. Ameha, S. Tadesse, A. Assefa, and B. Tessema, "Prevalence and associated factors of Hepatitis $\mathrm{C}$ virus and human immunodeficiency virus infections among voluntary counseling and testing clients attending private health facilities in Bahir Dar city, North West Ethiopia 2014," BMC Research Notes, vol. 12, p. 693, 2019.

[77] S. Abdella, T. Moshago Berheto, G. Tolera et al., "Seroprevalence of transfusion transmittable infections: HIV, Hepatitis B, C and Treponema pallidum and associated factors among blood donors in Ethiopia: a retrospective study," PLoS One, vol. 15, Article ID e0241086, 2020.

[78] M. Abebe, B. Alemnew, and S. Biset, "Prevalence of hepatitis $B$ virus and hepatitis $C$ virus among blood donors in nekemte blood bank, Western Oromia, Ethiopia: retrospective 5 years study," Journal of Blood Medicine, vol. 11, p. 543, 2020.

[79] M. A. Asemahagn, "Epidemiology of hepatitis B and C virus infections among patients who booked for surgical procedures at Felegehiwot referral hospital, Northwest Ethiopia," PLoS One, vol. 15, Article ID e0234822, 2020.

[80] G. Ayano, K. Haile, A. Tesfaye et al., "Undiagnosed HIV, hepatitis $\mathrm{B}$, and hepatitis $\mathrm{C}$ infections in people with severe psychiatric disorders in Ethiopia," BMC Infectious Diseases, vol. 20, pp. 1-9, 2020.

[81] A. Ayele, D. Abera, M. Hailu, M. Birhanu, and K. Desta, "Prevalence and associated risk factors for Hepatitis B and C viruses among refugees in Gambella, Ethiopia," BMC Public Health, vol. 20, pp. 1-10, 2020.

[82] T. A. Bafa and A. D. Egata, "Seroepidemiological patterns and predictors of hepatitis B, C and HIV viruses among pregnant women attending antenatal care clinic of Atat Hospital, Southern Ethiopia," SAGE Open Medicine, vol. 8, 2020.

[83] M. Dagnew, Y. Million, M. Gizachew et al., "Hepatitis B and $\mathrm{C}$ viruses' infection and associated factors among pregnant women attending antenatal care in hospitals in the Amhara national regional state, Ethiopia," International Journal of Microbiology, vol. 2020, Article ID 8848561, 11 pages, 2020.

[84] A. A. Kabato and G. M. Weldearegay, "Prevalence and associated risk factors of Hepatitis B and Hepatitis C virus among volunteer blood donors in Arba Minch Blood Bank SNNPR, Ethiopia," Journal of Medical Laboratory and Diagnosis, vol. 7, pp. 20-27, 2016.

[85] A. K. Ziraba, J. Bwogi, A. Namale, C. W. Wainaina, and H. Mayanja-Kizza, "Sero-prevalence and risk factors for hepatitis B virus infection among health care workers in a tertiary hospital in Uganda," BMC Infectious Diseases, vol. 10, p. 191, 2010. 
[86] M. Lemoine, S. Nayagam, and M. Thursz, "Viral hepatitis in resource-limited countries and access to antiviral therapies: current and future challenges," Future Virology, vol. 8, no. 4, pp. 371-380, 2013.

[87] S. Mahmud, V. Akbarzadeh, and L. J. Abu-Raddad, "The epidemiology of hepatitis $C$ virus in Iran: systematic review and meta-analyses," Scientific Reports, vol. 8, p. 150, 2018.

[88] K. Chaabna, S. P. Kouyoumjian, and L. J. Abu-Raddad, "Hepatitis C virus epidemiology in Djibouti, Somalia, Sudan, and Yemen: systematic review and meta-analysis," PLoS One, vol. 11, Article ID e0149966, 2016.

[89] M. M. Badawi, M. S. Atif, and Y. Y. Mustafa, "Systematic review and meta-analysis of HIV, HBV and HCV infection prevalence in Sudan," Virology Journal, vol. 15, p. 148, 2018.

[90] B. A. Muzembo, T. Akita, T. Matsuoka, and J. Tanaka, "Systematic review and meta-analysis of hepatitis $\mathrm{C}$ virus infection in the Democratic Republic of Congo," Public Health, vol. 139, pp. 13-21, 2016.

[91] J. J. Bigna, A. M. Kenne, A. Hamroun et al., "Gender development and hepatitis $\mathrm{B}$ and $\mathrm{C}$ infections among pregnant women in Africa: a systematic review and meta-analysis," Infectious Diseases of Poverty, vol. 8, p. 16, 2019.

[92] M. A. Hassan-Kadle, M. S. Osman, and P. P. Ogurtsov, "Epidemiology of viral hepatitis in Somalia: systematic review and meta-analysis study," World Journal of Gastroenterology, vol. 24, no. 34, pp. 3927-3957, 2018.

[93] Z. Al Kanaani, S. Mahmud, S. P. Kouyoumjian, and L. J. AbuRaddad, "The epidemiology of hepatitis $\mathrm{C}$ virus in Pakistan: systematic review and meta-analyses," Royal Society Open Science, vol. 5, no. 4, Article ID 180257, 2018.

[94] J. J. Bigna, M. A. Amougou, S. L. Asangbeh, A. M. Kenne, and J. R. Nansseu, "Seroprevalence of hepatitis C virus infection in Cameroon: a systematic review and meta-analysis," BMJ Open, vol. 7, Article ID e015748, 2017.

[95] Y. Gao, J. Yang, F. Sun et al., "Prevalence of anti-HCV antibody among the general population in mainland China between 1991 and 2015: a systematic review and metaanalysis," Open Forum Infectious Diseases, vol. 6, no. 3, p. ofz040, 2019.

[96] L. Platt, P. Easterbrook, E. Gower et al., "Prevalence and burden of HCV co-infection in people living with HIV: a global systematic review and meta-analysis," The Lancet Infectious Diseases, vol. 16, no. 7, pp. 797-808, 2016.

[97] R. E. Barth, Q. Huijgen, J. Taljaard, and A. I. M. Hoepelman, "Hepatitis B/C and HIV in sub-Saharan Africa: an association between highly prevalent infectious diseases. A systematic review and meta-analysis," International Journal of Infectious Diseases, vol. 14, no. 12, pp. e1024-e1031, 2010.

[98] F. B. Amiri, E. Mostafavi, and A. Mirzazadeh, "HIV, HBV and HCV coinfection prevalence in Iran-a systematic review and meta-analysis," PLoS One, vol. 11, Article ID e0151946, 2016.

[99] S. P. Kouyoumjian, H. Chemaitelly, and L. J. Abu-Raddad, "Characterizing hepatitis C virus epidemiology in Egypt: systematic reviews, meta-analyses, and metaregressions," Scientific Reports, vol. 8, p. 1661, 2018.

[100] X. Gao, Q. Cui, X. Shi et al., "Prevalence and trend of hepatitis $\mathrm{C}$ virus infection among blood donors in Chinese mainland: a systematic review and meta-analysis," $B M C$ Infectious Diseases, vol. 11, p. 88, 2011.

[101] M. Khodabandehloo, D. Roshani, and K. Sayehmiri, "Prevalence and trend of hepatitis $\mathrm{C}$ virus infection among blood donors in Iran: a systematic review and meta-analysis," Journal of Research in Medical Sciences: The Official Journal of Isfahan University of Medical Sciences, vol. 18, p. 674, 2013. 